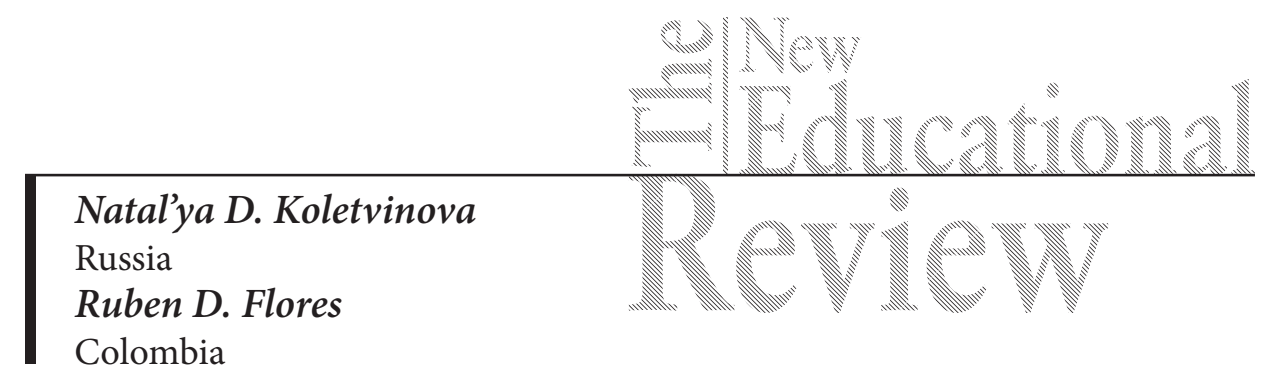

\title{
Priorities for the Evaluation Function of Teacher Education University Students' Competency-Based Training
}

DOI: 10.15804/tner.2015.41.3.15

\begin{abstract}
The relevance of this problem is related to an insufficient degree of the development of the issue of identifying the evaluation function of the competence-based training of students. The research objective: to identify and systematize, on the basis of the functional analysis of the knowledge-resource capacity of the teacher's professional polyfunctional activity, the priority components that can be considered as indicators of quality and effectiveness of the competency-based training. The leading technologies to the study of this problem are the technologies of mastering the types of speech activity with adequate speech design, aspect-integrated learning, self-activation, personality-oriented communication, etc. In the article there are reflected the results of this work, during which students mastered the characteristics of the professional communication as important indicators of the quality level of the professional communicative competency. The article contents can be useful for practical professional activity of teachers of higher education institutions and high school teachers.
\end{abstract}

Keywords: presentation characteristic, conative characteristic, phatic characteristic, competency, interpretation, text, adequacy of speech design, integration relations, designing, monologue speech, dialogized communication

\section{Introduction}

The expansion of the range of issues of improving the effectiveness of students' professional readiness is significantly associated with an innovative approach to the process of education. Among the important problems at present there is the 
problem of "tutors of teaching activities and a new ideology of teacher training in higher education institutions" (Gabdilkhakov, 2014). The scientific community places higher demands on the professional activities of the teacher in the conditions of market relations (Zakirova, 2014). Inclusion in the educational process of the advanced complex of scientific-pedagogical resources creates a fairly holistic professionally-oriented picture of the goals and objectives of prospective teachers' necessary and sufficient competency-based training. Much attention is paid to the problem of evaluating the quality and effectiveness of the communicative competencies being developed. It meets the requirements of modern society, because it meets teachers' needs of innovative orientation. However, the scientific community considers this issue ambiguously (Efremova, 2012).

Most scientists are inclined to the idea of using high innovative technologies to improve the quality of students' competency-based training (Kudryavtseva, 2012; Karavaeva, 2014).

This approach requires a new way to look at the problem, analysis of new aspects of the methods, as well as principles and approaches that will further bring the dominating performance evaluations of the multi-level professional communicative competency, providing a high quality of education.

This is due to inferring the quality indicators and the competency function performance in practice.

Students' mastery of the competency-based training quality indicators is appropriate to be carried out on the basis of the specially developed strategic set of priority components of certain communicative competencies. In the role of the indicators there are the characteristics of professional communication, specifically worked out for the main types of professional communication of teachers with an adequate speech design.

Mastering the characteristics as quality indicators of professional activity allows for introducing students to the field of mastering the effective professional competency at an early stage of learning.

\section{Methodological Framework}

Scientific approaches to the problem of increasing the effectiveness of the professional competency-based training of the students of teacher education universities are very diverse. The communicative approach, the predictive communication method, the implementation of integration relations, the aspect-inte- 
grated learning, the method of contextual guessing, text interpretation, dialogized communication, the search method, etc., are considered. Professional competencies are considered from the perspective of the priority and significance of their components, as well as in the context of creativity development of the teacher. Relying on the requirements, "the teacher needs to be ready for organizing and executing various types of teaching" (Kamalova, 2015). In scientific papers these technologies are analyzed in terms of finding new aspects, aimed at improving cognitive activity and quality of student learning. The unifying principle of all the views of scientists is the creative development and striving to build the educational process on the basis of self-organization, self-learning and self-development (Andreev, 2012). These qualities are important for modern teachers, as they ensure their demand on the labor market and their competitiveness. The teacher has an important task of educating students to the needs for knowledge, understanding of its significance, practical and axiological necessity. In line with this, one of the important directions of modern education is the widespread use of learning awareness, personal activity, aesthetic, and ethic-axiological approaches. The basic direction of the teacher's activity is to ensure balanced development of all the components of the educational process, contributing to the formation of a school of joy and creativity.

\section{Results}

The objectives of identifying the priority indicators of the student's professional communicative competency development

The appropriateness of the allocation of priority indicators for the development of students' professional communicative competency as indicators of progress in the acquisition of the necessary and sufficient competency components is due to the concentration in them of professionally dominant types, methods, actions and focal points of professional communication. The excretion of the indicators was determined by the following conditions: identification of the priority types for professional communication; formulation on their basis of significant characteristics of the professional communication with the corresponding components of professional activity; determining the features of the functioning characteristics of professional communication in various spheres of professional multifunctional activity. The need to identify the priority components of different competencies in the process of practice-based learning is due to several factors, the chief among 
which are the inability of students to build professional communication with a view to its speech design, the ignorance of the basic requirements of professional speech communication, lack of understanding of the need for strict speech fixedness for each type of professional communicative activities of the teacher. Mastering these competency components is an important condition for the formation of the main factors of successful competency-based training. To achieve these objectives, we developed a special system complex of communicative tasks with a predominance of creative activities.

\section{The initial stage of mastering the presentation characteristics of professional communication}

At the first stage of the professional practice-oriented training, the basics of mastering a high level of communicative language competency were analyzed, which is the main starting point for assessing the effectiveness of competency-based training. At the beginning of the work, the diagnostics was carried out for determining the level of psychological readiness of students to perceive multilevel professionally-oriented material saturated with information. The level of vocabulary for professional orientation was determined, knowledge of professional speech peculiarities. The diagnostics showed an insufficient level of psychological readiness of students to perceive the professional polyfunctional orientation information material. Since the presentation feature is implemented on the basis of information communication, it was found that students needed to know and to apply the basics of language competence in the communicative-activity aspect. In line with this, special professionally-oriented tasks of varying complexity were developed, meeting the requirements of the basic level of inclusion of students in the practice-oriented professional competency-based training.

The tasks included tests, thematic situation-driven exercises, reflection questions, analysis of the texts. The main form of instruction here is the form of interconnected teaching of the language skills. A priority at this stage is given to the communicative technology of aspect-integrated learning, the technology of motivational rationale, focus on the addressee, and the search method.

At the first stage of mastering the presentation characteristics, the students' attention was drawn to the criteria of the information communication in general. The students were working on the substantive and procedural nature of the profession-oriented material, the composite-speech design characteristics, analyzing the stylistic-communicative relevance of the material to its target and content assumptions, considering the level of its substantial focus on the recipient, but 
they were also working on the compliance of the informative saturation of the material with the used speech means and the consideration of the contingent of the students from the standpoint of their possible connection to joint creativity. Students get satisfaction from this work, gradually accumulating experience of the future professional activity (McKenzie, 2001). Such work requires active assistance of the teacher, who at each stage implements feedback followed by a discussion (Race, 1993). At the first stage, the students' knowledge about the types of the professional activity of the teacher is fixed with the use of adequate speech design. These skills represent a kind of professional data bank with which the students work at the next stages of learning.

\section{The presentation characteristics of professional communication}

At the second stage of the competency-based training, presentation characteristics are seen from the perspective of the communicative and active learning methods, with the closest approximation to the professional multifunctional activity of the teacher.

At this stage, priority is given to the principle of active communication, technology of communication, differentiation of language means, text interpretation, the research method, the reflective method, and the method of implementation of integration relations. Students determine the role of the most important competency aspects of the presentation characteristic, perform tasks using the concepts of logical nature, and drill the competencies of the scientific content material transition from the pre-communicative phase to communication. The work is focused on the development of students' perceptions of the teacher's polyfunctional professional activity components, professional opportunities of monologue speech. Students project profession-oriented situations with certain competency components with adequate speech design. Students' attention is focused on the appropriateness of differentiating the types of professional speech activity and their availability.

Priority in these types of work is given to the principle of encouraging and supporting intrinsic motivation (Conner, 2006). An important role is played by preparation of fragments of classroom-based presentations on the basis of the information-saturated monologue material of various genres. During the presentation, methods of contextual guessing and implementation of the predictive communication integration relations are used. Such work largely contributes to the development of competency in monologue speech, which is an important component of the effectiveness of the competency-based training. In addition, 
performing such tasks develops in students the desire for self-acquisition of professional competencies that meet the needs of modern society (Implementation, 2010). The work on mastering the basics of presentation characteristics is completed with a test, in which indicators of the quality and effectiveness of the professional competency orientation monologue speech are widely used. This is followed by a team discussion on the quality level of the competency being used, with comments and evaluation of its components.

\section{Phatic characteristic of communication}

The third stage of professional practice-based learning is built on the basis of mastering the components of the phatic characteristic of professional communication. The phatic characteristic is implemented in all types of professional activity. Bringing it up as a priority for the learning process is connected with the motivation-focused and content-procedural aspects of the teacher's professional communicative activities.

Reviewing it as an indicator of the effectiveness of students' competency learning is due to its significance in the development of the competency components of goal-setting and motivation of professional communication training that opens the way to mastering the competency of training organization.

The mastery of the phatic characteristic of professional communication is carried out on the basis of specially designed tasks of various nature: tasks to define and clarify the objectives of the proposed actions with the purpose of attracting students to creative cooperation; tasks consisting in cumulative consolidation of the stated material to enhance the interest in studying it; tasks for appropriate inclusion of unplanned forms of professional communication without disturbing the main substantive outline of the lesson. When performing them, students design fragments of classes with further justification of the selected speech means, specifying the objectives and the used creative and research methods. At this stage, students develop the contact-setting, communicative-organizational, informative-communicative competency skills, and also the competencies of communicative-creative interaction.

Priority at the third stage is given to the competence-forming technologies, criteria-based methods, and the principle of situational and thematic organization of learning, the realization of integration relations method.

The mastery of the phatic characteristic contributes to the development of such priority competency components as the motivational-target component, communicative-organizational component, communicative-stimulating component, 
which can be regarded as quality indicators of implementing the communicative competency in general. The possession of these components provides sufficient performance for practical competency-based activities.

\section{The connotative characteristic of communication}

The fourth stage of professional practice-based learning is built on the basis of mastering the connotative characteristics of professional communication as an indicator of the effectiveness of student competency learning. The importance of a quality indicator of the characteristic is caused by such functions for professional communication as regulation of attention, volition, motivation, attracting attention, expression of the attitude to the addressee and the situation.

Task performance of regulating attention correlates with the students' mastery of such important professional performance as a clear perspective of the practical necessity to execute an activity. The urge to draw attention is associated with the development of a generalized communicative-contact competency. Volition is characterized by certain striving to achieve the desired result during an explanation or survey. Speech-making of the kinds of professional activity in the students' performance at this stage relies on individual character.

At this stage, the communicative approach is widely used, as well as the student-oriented communication, the principle of interaction of the main types of speech activity, of the situational and thematic organization of educational material, technologies of intellectual development, the problem-search method, the research method, the self-motivation technique, etc. Specifically designed tasks were aimed at developing the students' communicative and creative qualities, as well as such competency components as communicative-regulatory, communicative-incentive, and communicative-interactive. Students independently prepare fragments of classes, perform situation-driven tasks using creative methods, and develop lessons using research methods. Students actively speak on the topical issues of developing professional competency, the problem-oriented discourses (Sleeman, 1992). Active participation in intellectual communication is the impetus for developing the cognitive independence of an individual (Miller, 1990). The separation of the intellectual information into "the studied" and "the new" in the characteristics of professional communication contributes to the acquisition of a new knowledge on a standalone basis, relying on the implementation of integration relations (Prince, 1981).

As an indicator of the quality and effectiveness of the professional communicative competency, the connotative characteristic realizes itself in such principles as 
clear, accessible presentation of a material. These principles are at this stage used by students during their preparation of a lecture lesson, discussion lesson, using creative and research methods.

\section{Discussions}

Studies on the evaluation of the effectiveness and quality of the competency learning reflect the diversity of scientific perspectives and unresolved issues. This issue is of importance and is reflected in the scientific works of various scholars: the competence-based approach is considered as a measure of education (Tkhagapsoev, 2013), the quality components indicators of the core competencies are analyzed (Afanasiev, 2013) adequately enough, the problem of the assessment tools fund and the problem of creating a grading system of the university are considered, the problem of determining exactly what results form a particular professional competency is being examined, etc.

In the concepts of foreign scholars there is a focus on the ethical and reflective aspect of evaluating competency-based training performance (Rbodes, 2001), the problem of reflecting the effectiveness and quality of competency-based training in the process of solving practical tasks of professional activity is analyzed (Vebter, 2010), the dependence of the efficiency of mastering the competencies on the improvement of the diagnostic tools of learning is examined (Castro, 2009), etc.

However, no consensus on the issue of quality assessment of the competency-based training of students up to the present has been developed by the scientific community. The foundations of the substantive-procedural filling of those or other professional competencies have not been defined, there is no single approach to their formation at university, the alignment of the competencies with the program material of various disciplines has not been defined, etc.

In the basis of this article there is the aspect of determining the priority components of individual competencies as indicators of the quality and effectiveness of competency-based student learning, which did not receive proper development. For this purpose, features for professional communication were specially designed, which allow for determining the necessary and sufficient performance and quality indicators of the practical application of the communicative competencies being developed. Priority is given to research, reflexive, differentiated and communication technologies.

The research has shown the effectiveness of the range of approaches and methods for facilitating professional communication training of students. Most 
students were distinguished by a high level of quality of mastering the professional communicative competencies on the basis of the derived indicators.

Thus, the article reflects the results of the work done on mastering the priority competency components on the basis of practice-based learning. The article contents can be used in the practical professional activities of university professors and high school teachers.

\section{Conclusions}

The obtained results in the course of the systematic and purposeful work showed that the level of mastering the priority competency components - the indicators of the quality and effectiveness of the practical application of the professional communication competencies - meets the requirements of modern education. The students have mastered the necessary and sufficient functional characteristics of professional communication, learned the methods and techniques of their use in the context of goal-setting and motivation of all kinds of professional communicative activity with an adequate speech design.

The students learned to navigate in a functional space of the used competencies, identifying specific factors of the effectiveness on the target nature of learning. The selection of priority technologies, methods, forms and ways of professional activity was determined by their correlation with the indicators of the competency orientation quality in the aspect of the interrelatedness of learning with the types of speech activity. The students determined the important professional-communicative components for the teaching profession, the necessary personal qualities, the independency qualities, analyzed the essence of the concept of "indicators of quality and effectiveness of competency-based training." The students demonstrated mastery of the professional speech activity, subject to the requirements of the characteristics of professional communication and the specifics of the multifunctional activity of the teacher. The pedagogical conditions of the work were considered by the students in the context of their professional, axiological, ethical, aesthetic potential, creativity and relevance to the professional activity of the teacher.

The conducted research led to the following conclusions: the system approach has been implemented in the development of the professional competency-based training of students by improving its quality and effectiveness. The indicators of estimating the efficiency of using the communicative competencies in the polyfunctional professional activity of the teacher have been derived, as well as their 
substantive-procedural richness and specificity of the professionally-oriented applications. Pedagogical conditions of using the characteristics of professional communication at the level of various types of the professional communicative activity with an adequate speech design have been defined. The means of providing interconnections and interactions of all the components of the professional activity of the teacher on the basis of the competency approach have been defined. The professional guidelines of selecting the quality indicators of competency-based training have been presented, depending on the motivational goals of various kinds of professional activities. Specially elaborated tasks contribute to the development of independency qualities of future teachers in the context of modern requirements of training and education. The use of the reflective, communicative-active, differentiated and creative approaches in the professional training of students as a factor in achieving efficiency and effectiveness in the application of the relevant competencies in the professional activity of the teacher has been analyzed.

\section{Acknowledgments}

The work was performed according to the Russian Government Program of Competitive Growth of Kazan Federal University.

\section{References}

Afanasiev, D. V. \& Gryzlov V. S. (2013) The competence-based approach and the credit-modular system of training. Higher education in Russia, 6, 11-18.

Andreev, V. I. (2012) The retrospective and prognostic approaches to the development of the concept of the subject-oriented teacher education for creative self-development of students - future teachers. Education and self-development, 5(33).

Castro, M. E., Niño A. \& Muñoz-Caro C. (2009) GMAT. A software tool for the computation of the rovibrational g matrix. Computer Physics Communications, Vol.180, 7, $1183-1187$.

Conner, M. (2006) Andragogy + Pedagogy. - URL: http://agelesslearner.com/intros/ andragogy.html.

Efremova, N. F. (2012) Quality assessment as a guarantee of the competence-based learning of students. Higher education in Russia, 11, 119-125.

Gabdilkhakov, V.F., A.M.Kalimullin (2014) Tutoring of pedagogical activity and new ideology of teacher training in the higher education institution. Life Science Journal, 11(11s), 183-187. 
Implementation of "Education and training 2010" work programme. (2010) Working group B: "Key Competences”. Key Competences for Lifelong Learning. A Europian Reference Framework. November. http://europa.eu.int/comm./education/policies/2010/ doc/basicframe.pdf.

Kamalova, L.A. (2015) Formation of Professional Competences of "Primary Education» Profile Students While the Studying Process at the University. Review of European Studies, 7(1), 94-100.

Karavaeva, E. V. (2014) The recommended algorithm for designing higher education programs. Higher education in Russia, 8-9, 5-15.

Kudryavtseva, E. (2012) Modern approaches to the problem of forming and using the competency models. Management consulting. Actual problems of the state and municipal management, 1, 166-177.

McKenzie, J. (2001) How Teachers Learn Technology Best. The Educational Technology Journal, 10(6). http://fno.org/mar01/howlearn.html.

Miller, G. A. (1990) Linguists, psychologists, and the cognitive science. Language, Vol.66, 2, 317-322.

Prince, E. (1981) Toward a taxonomy of given/new information. Radical pragmatics. N.Y., 223-235.

Race, Ph. (1993) Never mind the teaching - feel the learning. SEDA Paper 80, June, Birmingham.

Rbodes, F. T. (2001) The creation of the future: The role of the American university. Ithaca, 34.

Sleeman, D. (1992) Intelligent Tutoring Systems. New York: Academic Press.

Thagapsoev, Kh.G. (2013) Competency-based education: to the problem of the incarnation. Higher education in Russia, 6, 71-76.

Vebter, E. V. \& Safyannikov I.A. (2010) Project-Organised Learning Method in the System of Engineering Education of Russia by the Example of National Research Tomsk Polytechnic University. Second Ibero-American Symposium on Project Approaches in Engineering Education (PAEE’2010): Creating Meaningful Learning Environments. Barcelona, 97-100.

Zakirova, V. G. \& Koletvinova N. D. (2014) Paradigm of future primary school teachers' vocational training. Life Science Journal, 11(4), 441-447. 